\title{
Updates in arteriovenous malformation management: the post-ARUBA era
}

\author{
James Feghali (D), Judy Huang
}

To cite: Feghali J, Huang J. Updates in arteriovenous malformation management: the post-ARUBA era. Stroke \& Vascular Neurology 2020;5: e000248. doi:10.1136/svn2019-000248

Received 4 May 2019

Revised 31 May 2019

Accepted 3 September 2019

Published Online First

21 September 2019
Check for updates

(c) Author(s) (or their employer(s)) 2020. Re-use permitted under CC BY-NC. No commercial re-use. See rights and permissions. Published by BMJ.

Department of Neurosurgery, Johns Hopkins University School of Medicine, Baltimore, Maryland, USA

Correspondence to Dr Judy Huang; jhuang24@jhmi.edu

\section{ABSTRACT}

Brain arteriovenous malformations (AVMs) are complex and heterogeneous lesions that can rupture, causing significant morbidity and mortality. While ruptured lesions are usually treated, the management of unruptured AVMs remains unclear. A Randomized trial of Unruptured Brain Arteriovenous Malformations (ARUBA) was the first trial conducted to compare the effects of medical and interventional therapy. Although it concluded that medical therapy was superior in preventing stroke and death over a follow-up period of 33 months, the findings were met with intense criticism regarding several aspects of study design, progression, and analysis/conclusion. Namely, the increased use of stand-alone embolisation relative to microsurgery in a cohort with predominantly low-grade lesions combined with a short follow-up period amplified treatment risk. Subsequently, several observational studies were conducted on ARUBA-eligible patients to investigate the safety and efficacy of microsurgery, radiosurgery, and endovascular embolisation over longer follow-up periods. These reports showed that favourable safety profiles and cure rates can be achieved with appropriate patient selection and judicious use of different treatment modalities in multidisciplinary centres. Since large prospective randomised trials on AVMs may not be feasible, it is important to make use of practice-based data beyond the flawed ARUBA study to optimise patients' lifetime outcomes.

\section{INTRODUCTION}

Brain arteriovenous malformations (AVMs) are rare cerebrovascular lesions characterised by an abnormal mass of dilated arteries and veins and direct arteriovenous shunting. ${ }^{2}$ They are usually discovered during young adulthood and can present with headaches, seizures, or most commonly, intracranial haemorrhage, which can cause significant morbidity and mortality. ${ }^{3}{ }^{4}$ Since the first AVM surgical exposure by Giordano and the first successful AVM resection by Péan in $1889,{ }^{5}$ the treatment of these heterogeneous lesions has evolved along with several innovations in the fields of microneurosurgery, radiosurgery, and endovascular neurosurgery. ${ }^{6}$ Currently, AVMs are managed by either medical management with watchful follow-up or using the following modalities alone or in combination: surgical resection, stereotactic radiosurgery or embolisation. ${ }^{7}$
In a patient-level meta-analysis of 2525 patients with 6074 patient-years of follow-up, the annual rate of AVM haemorrhage was around four times higher in lesions that presented with haemorrhage (4.8\%) compared with unruptured AVMs at baseline $(1.3 \%) .^{8}$ As a result, ruptured lesions are generally treated to mitigate the risks of rebleeding. However, in the absence of robust data on natural history and treatment risk, the management of unruptured AVMs presents a challenge. ${ }^{9}$ In an effort to address this knowledge gap, A Randomized Trial of Unruptured Brain Arteriovenous Malformations (ARUBA) was conducted and was the first completed randomised prospective clinical trial comparing the effects of medical versus interventional therapy. ${ }^{10}$ After an interim analysis of results, the trial was halted prematurely, and its findings were met with profound criticism. As the study represents a landmark trial in the modern era of AVM patient care, we sought to provide a summary of the major findings and criticisms of ARUBA while providing an overview of the main studies that followed and the current status of AVM management.

\section{ARUBA SUMMARY}

Having been launched in 2006, the trial initially involved 104 clinical sites across nine countries and consisted of a randomised, prospective, parallel and open-label design (https:// clinicaltrials.gov/ct2/show/ NCT00389181). Patients were allocated to either medical management or medical and interventional therapy, including surgery, radiotherapy, and embolisation, alone or in any combination. The main hypothesis tested was that no difference exists between medical management and interventional therapy in the time to symptomatic stroke or death from any cause, the primary outcome of the study. The original recruitment plan was to enrol 800 patients which provides $87.5 \%$ power in detecting a $40 \%$ reduction in the risk stroke or death. Since recruitment was very slow, target sample size was decreased to 


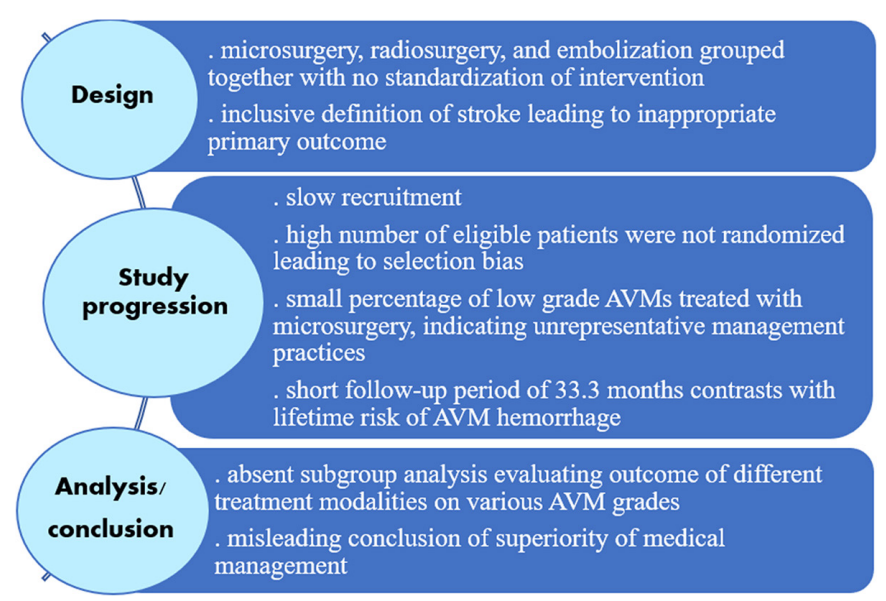

Figure 1 Main criticisms of ARUBA summarised by trial phase. ARUBA, A Randomized trial of Unruptured Brain Arteriovenous Malformations; AVM, arteriovenous malformation.

400 patients which provided $80 \%$ power in detecting a $46 \%$ reduction in risk. After a 6-year period, an interim analysis was conducted on 223 patients who had been enrolled and followed up for a mean of 33.3 months. Out of 109 patients in the medical treatment arm, $11(10.1 \%)$ reached the primary endpoint compared with 35 (30.7\%) of the 114 patients in the intervention group. ${ }^{10}$ Due to this threefold difference in outcome-free survival and the increased hazard in the intervention group, the study was halted prematurely.

\section{ARUBA-COMMENTS \& CRITICISM}

Despite several concerns regarding different aspects of the trial, the baseline patient characteristics confirm an adequate randomisation process, whereby both arms were appropriately matched in demographics, functional status, lesion size, location, and venous drainage pattern. ${ }^{10}{ }^{11}$ The results obtained were also similar to a non-randomized, prospective, population-based cohort study of 204 patients in Scotland that showed a greater hazard for handicap (Oxford Handicap Scale score of 2-5) among patients who underwent interventional therapy over a median follow-up of 6.9 years. ${ }^{12}$ The critiques of ARUBA can be divided according to the three main phases of the trial: design, study progression and analysis/conclusion. A summary of the main criticisms is provided in figure 1 .

\section{Design}

At the design level, the trial was heavily criticised for not standardising the treatment arm since each intervention has its own risks, indications and considerations. ${ }^{13-17}$ This approach makes it difficult to draw conclusions about the utility of each individual management strategy. ${ }^{18}$ In addition, it provides little information about which particular treatment is superior in a specific patient, limiting the insight gained in terms of real-world decision-making. ${ }^{19}$ Even though all three modalities of treatment were grouped together for comparison purposes with no randomisation at the level of every intervention, it would have been useful to show the results obtained for each therapeutic approach. ${ }^{20}$ Further, no details were provided about the treatment process itself. Embolisation procedures may be serial, and radiotherapy varies in type (gamma knife, linear accelerator etc) and dosage, which may impact outcomes. ${ }^{11} 17$

In any clinical trial, the choice and definition of the primary outcome can heavily impact the results and their interpretation. In ARUBA, stroke was defined as the occurrence of any clinical symptom, including seizure or new-onset headache, in association with new intracranial blood or a new ischaemic lesion on CT or MRI. ${ }^{10}$ The reasoning behind this low threshold for stroke diagnosis is that unruptured lesions are often asymptomatic and hence, any new symptom or radiological sign should be considered as a negative effect of therapy. ${ }^{21}$ Yet, imaging changes and mild clinical symptoms such headache or postintervention seizure may occur with no significant effect on permanent morbidity; consequently, this choice of primary outcome may inflate treatment risks. ${ }^{1422}$

\section{Study progression}

Concerning the progression of the study, the recruitment of patients was slow and limited to fewer centres than had been originally planned. ${ }^{23}{ }^{24}$ This could be partly attributed to the absence of clinical equipoise in some cases, whereby patients considered to have a high risk of rupture by investigators were excluded from study enrolment. ${ }^{11}$

The generalisability of trial results is closely tied to the representativeness of the study population. With respect to ARUBA, the high degree of selection bias considerably limited the external validity of the results and conclusions obtained. For instance, most of the included patients were treated in European participating centres, namely Germany $(\mathrm{n}=51 ; 23 \%)$ and France $(\mathrm{n}=79 ; 35 \%)$, which may not reflect North American practice. ${ }^{11}$ Moreover, out of the 1740 patients who were screened for potential inclusion, 726 patients were eligible, but only 226 were randomised. Of the remaining 500 patients, 177 were managed outside of randomisation and 323 declined enrolment. ${ }^{11}{ }^{17}$ The characteristics of the 177 patients and their AVMs are not known, as no registry was created to follow-up their outcomes. ${ }^{17}$ Also, the reasons behind refusing enrolment with regards to the other 323 patients were not discussed. ${ }^{11}$

In relation to effective lesion eradication, a major critique of ARUBA revolves around the choice of treatment modality for the patients belonging to the interventional therapy group. The neurosurgical literature recommends using microsurgical resection as the primary treatment modality for Spetzler-Martin grade I and II AVMs. ${ }^{25}$ Though $68 \%$ of patients in the treatment group harboured surgically favourable grade I or II AVMs, only 5 patients received microsurgery as standalone treatment, and 12 patients had embolisation with neurosurgery. On the other hand, most patients received embolisation alone $(n=30)$, radiotherapy alone 
$(n=31)$, or combined embolisation with radiotherapy $(n=15)$. Clearly, this distribution of treatment modalities employed, vis-à-vis the Spetzler-Martin grade of included AVMs, deviates significantly from standard practice in the USA and would predictably lead to suboptimal outcomes in the intervention arm. ${ }^{11} 192627$

Another main criticism of ARUBA is the short follow-up period. AVMs are chronic lesions that confer a lifelong risk of rupture. ${ }^{28}$ Over a follow-up time of 33 months, one would expect the immediate risks associated with intervention to be counted, while missing the possible protection against bleeding in the patients' lifetime as compared with natural history and expectant management. ${ }^{131719} 2930$

\section{Analysis and conclusion}

Given the broad inclusion criteria used in recruitment, the study participants and AVM lesions were heterogeneous, and in the absence of stringent treatment protocols, management strategies were also quite variable. Still, the authors did not conduct subgroup analyses where for example, the effect of different treatment modalities would be investigated in different strata of SpetzlerMartin grades. ${ }^{152} 2931$ This was most likely the result of having insufficient power from small sample sizes. ${ }^{15}$

The trial concluded that 'medical management alone is superior to medical management with interventional therapy for the prevention of death or stroke in patients with unruptured brain arteriovenous malformations followed up for 33 months'. ${ }^{10}$ Although the authors mentioned that angiography was used to check for lesion eradication in the Methods section, no quantitative data are presented in the results regarding eradication rates, and the timing of stroke in relation to eradication is not clear. In a trial where embolisation and radiosurgery are so heavily used, tracking and analysing data in relation to lesion eradication is crucial, especially since the literature indicates that partial AVM treatment likely provides no meaningful protection from haemorrhage. ${ }^{13233}$ When one considers the latency period between radiosurgery and total obliteration, the short follow-up period in this trial further emphasises the need for evaluating eradication. ${ }^{22}$ Because cure rates and management practices in the interventional arm were judged to fall below current standards, many authors deemed the final conclusion of this trial to be misleading or inappropriate. ${ }^{1734}$

\section{POST-ARUBA: MAJOR STUDIES}

In light of the shortcomings of ARUBA, many subsequent retrospective studies were conducted on ARUBAeligible patients. The studies constituted longer periods of follow-up to ensure that protective effects of treatment were evaluated. Unlike the trial, most of them restricted their analysis to a single main form of intervention to detect treatment-specific outcomes. A discussion of key studies is provided herein, organised by the principal intervention studied with a summary in table 1.

\section{Microsurgery}

Knowing that many included AVMs were surgically favourable, a central weakness of ARUBA was the relative paucity of microsurgical procedures performed. From a consecutive series of 288 patients with AVM, Schramm et al analysed their outcomes on 104 ARUBA-eligible patients who underwent microsurgical resection as the sole treatment modality. ${ }^{35}$ Over a mean follow-up period of 5.3 years, a permanent new significant deficit occurred in $7.7 \%$ of patients, and none of the patients experienced treatment-related mortality. ${ }^{35}$ This is much lower than the stroke or death rate encountered in both arms of ARUBA (medical arm: 10.1\%; treatment arm: $30.7 \%$ ) over a shorter follow-up period of 2.8 years. ${ }^{10}$ Importantly, the rate of permanent new significant deficits in low-grade AVMs (Spetzler-Martin grade I or II) was less than half that of higher-grade AVMs (3.2\% vs $7.7 \%) .{ }^{35}$ Functional outcomes also revealed a similar picture whereby poor modified Rankin scale scores were found in $10.4 \%$ of patients compared with $46.2 \%$ in the treatment arm of ARUBA. ${ }^{1035}$ These results were also mirrored by a study on 155 consecutive ARUBA-eligible patients with predominantly low-grade AVMs (72\%) that were treated primarily by microsurgery. The rate of permanent disabling deficits was $4.5 \%$ over a mean follow-up of 3 years, and major intraoperative bleeding ( $>1 \mathrm{~L}$ or transfusion of $>2$ units of blood) was the most significant predictor of permanent deficits. ${ }^{36}$ This association highlights the value of using preoperative embolisation as an adjunct that decreases procedural bleeding by addressing associated aneurysms and decreasing blood flow into the nidus.

\section{Radiosurgery}

It has been shown that the latency period between radiosurgery and total AVM obliteration is around 3 to 5 years $^{37}$; therefore, a follow-up period of 2.8 years was probably insufficient to adequately appraise the potentially protective effects of radiotherapy in ARUBA. To account for this limitation, Karlsson et al retrospectively evaluated 1351 ARUBA-eligible patients who were followed up over a mean of 6.5 years. ${ }^{38}$ Assuming a yearly haemorrhage risk of 2.2\% (as obtained in ARUBA), the cumulative incidence of stroke was compared between the medical treatment arm of ARUBA and the gammaknife radiosurgery (GKRS) arm of ARUBA-eligible patients with extrapolation up to 10 years. ${ }^{38}$ The analysis demonstrated similar stroke incidence for the first 5 years of follow-up after which the cumulative stroke incidence became higher in the medical ARUBA cohort; the difference in cumulative incidence kept increasing as follow-up time progressed beyond 5 years. ${ }^{38}$ When stratifying by AVM size, the study showed that a longer follow-up time may be needed ( $>11$ years) for large AVMs $\left(>5 \mathrm{~cm}^{3}\right)$ to demonstrate less morbidity and mortality on treatment compared with observation. ${ }^{38}$ These findings are similar to those of Pollock et al where radiosurgery patients with larger AVM volumes had a higher risk of stroke or death over a median follow-up of 5.3 years. ${ }^{39}$ 


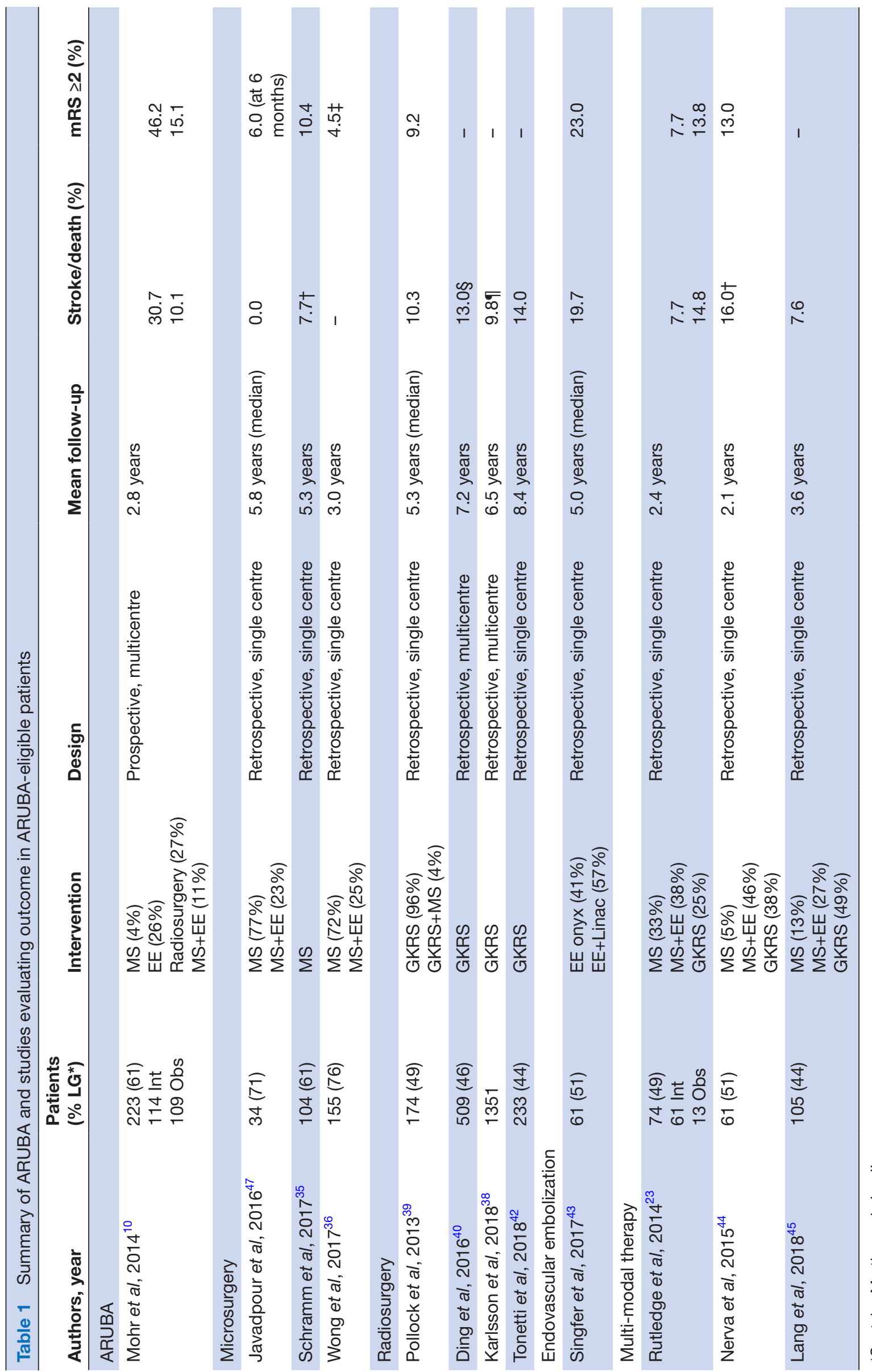


Further emphasising the effectiveness of radiosurgery, the rate of adverse neurological outcome (symptomatic radiation changes, post-radiosurgery haemorrhage, permanent neurological morbidity or death) over an average follow-up of 7.2 years was $13 \%$ in 509 patients treated with GKRS. ${ }^{40}$ The outcomes were more favourable when the authors reported results on 232 patients with low-grade AVMs. ${ }^{41}$ Although ARUBA did not report obliteration rates, the value of total eradication in recent studies on ARUBA-eligible patients varies between $70 \%$ and $80 \%{ }^{39-42}$ These studies have shown that over reasonable follow-up periods that surpass the latency period, treating unruptured AVMs with radiosurgery may lead to better outcomes than natural history.

\section{Endovascular embolisation}

A high proportion of ARUBA patients were treated with stand-alone endovascular embolisation (26\%) which was also a point of criticism. Singfer et al performed a retrospective analysis on 61 ARUBA-eligible patients, $41 \%$ of which were treated with stand-alone onyx embolisation and $57 \%$ of which were treated with onyx and Linac when necessary to attain cure ${ }^{43}$ During a median follow-up of 5 years, $20 \%$ suffered from stroke or death, and treatmentrelated mortality reached $7 \% .{ }^{43}$ Despite a selection bias toward patients with favourable profiles for endovascular therapy, treatment-related morbidity in this embolisationfocused approach was high, which may partially explain the elevated rate of adverse outcomes in the ARUBA interventional group.

\section{Multimodal therapy}

After ARUBA's controversial results, several analogous studies on ARUBA-eligible patients retrospectively reviewed their outcomes in series that included multimodal therapy. ${ }^{23} 4445$ Unlike ARUBA, the rates of standalone embolisation were negligible, and the use of microsurgery featured more prominently. Most recently, Lang et al reported results on 105 patients, $40 \%$ of which were treated by microsurgery with or without embolisation, followed up over an average of 3.6 years. ${ }^{45}$ They found a significantly lower rate of stroke or death when compared with that of the interventional group (7.6\% vs $30.7 \%$; $\mathrm{p}<0.0001)$ and conservative group $(10.1 \%)$ in ARUBA. ${ }^{45}$ Similarly, Rutledge et al reported lower rates of stroke or death in 13 conservatively managed $(7.7 \%)$ and 61 treated (14.8\%) ARUBA-eligible patients as compared with their ARUBA counterparts ( $10.1 \%$ and $30.7 \%$, respectively). ${ }^{23}$

\section{CURRENT MANAGEMENT PARADIGM}

While ARUBA had numerous limitations, it demonstrated that the treatment of unruptured AVMs does not come without cost. Still, it would be irresponsible to conclude that medical therapy and observation should be adopted as a universal management approach for all unruptured AVMs. ${ }^{19}$ Microsurgery remains a highly effective avenue for managing AVMs, especially low-grade lesions, and has been regarded as the gold standard of
AVM treatment given its favourable cure rates, safety profiles and immediacy. ${ }^{26} 3146$ The key to achieving good outcomes is appropriate patient selection in high-volume, multidisciplinary centres, ${ }^{47}$ whereby radiosurgery would play a more important role in deep, inaccessible lesions or those having an intimate association with eloquent cortex. A recent review of the literature regarding the use of endovascular embolisation with intent to cure in both ruptured and unruptured AVMs confirmed previous notions of increased complication rates and procedurerelated mortality. ${ }^{48}$ Chapot et al echoed this concern while highlighting the absence of robust data evaluating standalone embolisation in the interventional literature. ${ }^{49}$ Given existing reports, modern use of endovascular embolisation remains as an adjunct to microsurgery with the main goals of decreasing intraoperative blood loss in large AVMs and securing associated aneurysms or deep arterial feeders. In the aftermath of ARUBA, a new trial, BARBADOS (Beyond ARUBA-Randomized low-grade Brain AVM study: Observation vs Surgery) was proposed to confirm the utility of microsurgery. ${ }^{4650}$ Large prospective randomised trials will not likely be feasible for AVMs to inform our practice, so it is crucial to use the available practice-based data beyond the flawed ARUBA study to optimise patients' lifetime outcomes.

Contributors JH and JF both participated in the conception, drafting and approval of the manuscript.

Funding The authors have not declared a specific grant for this research from any funding agency in the public, commercial or not-for-profit sectors.

Competing interests None declared.

Patient consent for publication Not required.

Provenance and peer review Commissioned; externally peer reviewed.

Data availability statement All data relevant to the study are included in the article.

Open access This is an open access article distributed in accordance with the Creative Commons Attribution Non Commercial (CC BY-NC 4.0) license, which permits others to distribute, remix, adapt, build upon this work non-commercially, and license their derivative works on different terms, provided the original work is properly cited, appropriate credit is given, any changes made indicated, and the use is non-commercial. See: http://creativecommons.org/licenses/by-nc/4.0/.

ORCID iD

James Feghali http://orcid.org/0000-0001-7168-4751

\section{REFERENCES}

1 Friedlander RM. Arteriovenous malformations of the brain. $N$ Engl J Med 2007;356:2704-12.

2 Solomon RA, Connolly ES. Arteriovenous malformations of the brain. N Engl J Med 2017;376:1859-66.

3 Miller CE, Quayyum Z, McNamee P, et al. Economic burden of intracranial vascular malformations in adults: prospective populationbased study. Stroke 2009;40:1973-9.

4 Brown RD, Wiebers DO, Torner JC, et al. Frequency of intracranial hemorrhage as a presenting symptom and subtype analysis: a population-based study of intracranial vascular malformations in Olmsted country, Minnesota. J Neurosurg 1996;85:29-32.

5 Yasargil MG. Microneurosurgery: Thieme Classics. New York, NY: Thieme Medical Publishers, 1987.

6 Bendok BR, El Tecle NE, El Ahmadieh TY, et al. Advances and innovations in brain arteriovenous malformation surgery. Neurosurgery 2014;74:S60-73.

7 Lawton MT, Rutledge WC, Kim H, et al. Brain arteriovenous malformations. Nat Rev Dis Primers 2015;1. 
$8 \mathrm{Kim} \mathrm{H}, \mathrm{Al}$-Shahi Salman R, McCulloch CE, et al. Untreated brain arteriovenous malformation: patient-level meta-analysis of hemorrhage predictors. Neurology 2014;83:590-7.

9 Davis SM, Donnan GA. Unruptured brain arteriovenous malformations: another asymptomatic conundrum. Stroke 2007;38:3312.

10 Mohr JP, Parides MK, Stapf C, et al. Medical management with or without Interventional therapy for unruptured brain arteriovenous malformations (ARUBA): a multicentre, non-blinded, randomised trial. Lancet 2014;383:614-21.

11 Bambakidis NC, Cockroft KM, Hirsch JA, et al. The case against a randomized trial of unruptured brain arteriovenous malformations: misinterpretation of a flawed study. Stroke 2014;45:2808-10.

12 Al-Shahi Salman R, White PM, Counsell CE, et al. Outcome after conservative management or intervention for unruptured brain arteriovenous malformations. JAMA 2014;311:1661-9.

13 Pierot L, Fiehler J, Cognard C, et al. Will a randomized trial of unruptured brain arteriovenous malformations change our clinical practice? AJNR Am J Neuroradiol 2014;35:416-7.

14 Solomon RA, Connolly ES. Management of brain arteriovenous malformations. Lancet 2014;383:1634.

15 Day AL, Dannenbaum M, Jung S. A randomized trial of unruptured brain arteriovenous malformations trial: an editorial review. Stroke 2014;45:3147-8.

16 Bervini D, Morgan MK, Ritson EA, et al. Surgery for unruptured arteriovenous malformations of the brain is better than conservative management for selected cases: a prospective cohort study. $J$ Neurosurg 2014;121:878-90.

17 Russin J, Spetzler R. Commentary: the ARUBA trial. Neurosurgery 2014;75:E96-7

18 Elhammady MS, Heros RC. Editorial: the ARUBA study: where do we go from here? J Neurosurg 2017;126:481-5.

19 Amin-Hanjani S. ARUBA results are not applicable to all patients with arteriovenous malformation. Stroke 2014:45:1539-40.

20 Magro E, Gentric J-C, Darsaut TE, et al. Responses to ARUBA: a systematic review and critical analysis for the design of future arteriovenous malformation trials. J Neurosurg 2017;126:486-94

21 Houdart E. The need for new regulations on randomized clinical trials in surgical treatments. Neuroradiology 2010;52:1061-2.

22 Lawton MT, Abla AA. Management of brain arteriovenous malformations. Lancet 2014;383:1634-5.

23 Rutledge WC, Abla AA, Nelson J, et al. Treatment and outcomes of ARUBA-eligible patients with unruptured brain arteriovenous malformations at a single institution. Neurosurg Focus 2014:37:E8.

24 Bambakidis NC, Cockroft K, Connolly ES, et al. Preliminary results of the ARUBA study. Neurosurgery 2013;73:E379-81.

25 Spetzler RF, Ponce FA. A 3-tier classification of cerebral arteriovenous malformations. Clinical article. J Neurosurg 2011;114:842-9.

26 Knopman J, Stieg PE Management of unruptured brain arteriovenous malformations. Lancet 2014;383:581-3.

27 Mocco J, O'Kelly C, Arthur A, et al. Randomized clinical trials: the double edged sword. J Neurointerv Surg 2013;5:387-90.

28 Kondziolka D, McLaughlin MR, Kestle JR. Simple risk predictions for arteriovenous malformation hemorrhage. Neurosurgery 1995;37:851-5.

29 Meling TR, Proust F, Gruber A, et al. On apples, oranges, and ARUBA. Acta Neurochir 2014;156:1775-9.

30 Proust F, Roche P-H, Meling TR. Does ARUBA study improve our knowledge as regards the management of unruptured brain arteriovenous malformations? Neurochirurgie 2014;60:2-4.

31 Lawton MT. The role of AVM microsurgery in the aftermath of a randomized trial of unruptured brain arteriovenous malformations. AJNR Am J Neuroradiol 2015;36:617-9.

32 Karlsson B, Lax I, Söderman M. Risk for hemorrhage during the 2-year latency period following gamma knife radiosurgery for arteriovenous malformations. Int J Radiat Oncol Biol Phys 2001;49:1045-51.
33 Miyamoto S, Hashimoto N, Nagata I, et al. Posttreatment sequelae of palliatively treated cerebral arteriovenous malformations. Neurosurgery 2000;46:589-95.

34 Warlow C. Management of brain arteriovenous malformations. Lancet 2014;383:1632-3.

35 Schramm J, Schaller K, Esche J, et al. Microsurgery for cerebral arteriovenous malformations: subgroup outcomes in a consecutive series of 288 cases. J Neurosurg 2017; 126:1056-63.

36 Wong J, Slomovic A, Ibrahim G, et al. Microsurgery for ARUBA trial (a randomized trial of unruptured brain arteriovenous malformation)eligible unruptured brain arteriovenous malformations. Stroke 2017:48:136-44.

37 Shin M, Kawamoto S, Kurita H, et al. Retrospective analysis of a 10-year experience of stereotactic radio surgery for arteriovenous malformations in children and adolescents. $J$ Neurosurg 2002;97:779-84.

38 Karlsson B, Jokura H, Yang H-C, et al. The NASSAU (new assessment of cerebral arteriovenous malformations yet unruptured) analysis: are the results from the ARUBA trial also applicable to unruptured arteriovenous malformations deemed suitable for gamma knife surgery? Neurosurgery 2018;0:1-7.

39 Pollock BE, Link MJ, Brown RD. The risk of stroke or clinical impairment after stereotactic radiosurgery for ARUBA-eligible patients. Stroke 2013;44:437-41.

40 Ding D, Starke RM, Kano H, et al. Radiosurgery for cerebral arteriovenous malformations in a randomized trial of unruptured brain arteriovenous malformations (ARUBA)-eligible patients: a multicenter study. Stroke 2016;47:342-9.

41 Ding D, Starke RM, Kano H, et al. Stereotactic radiosurgery for ARUBA (a randomized trial of unruptured brain arteriovenous malformations)-eligible spetzler-martin grade I and II arteriovenous malformations: a multicenter study. World Neurosurg 2017:102:507-17.

42 Tonetti DA, Gross BA, Atcheson KM, et al. The benefit of radiosurgery for ARUBA-eligible arteriovenous malformations: a practical analysis over an appropriate follow-up period. $J$ Neurosurg 2018;128:1850-4.

43 Singfer U, Hemelsoet D, Vanlangenhove P, et al. Unruptured brain arteriovenous malformations: primary ONYX embolization in ARUBA (a randomized trial of unruptured brain arteriovenous malformations)eligible patients. Stroke 2017:48:3393-6.

44 Nerva JD, Mantovani A, Barber J, et al. Treatment outcomes of unruptured arteriovenous malformations with a subgroup analysis of ARUBA (a randomized trial of unruptured brain arteriovenous malformations)-eligible patients. Neurosurgery 2015;76:563-70.

45 Lang M, Moore NZ, Rasmussen PA, et al. Treatment outcomes of a randomized trial of unruptured brain arteriovenous MalformationEligible unruptured brain arteriovenous malformation patients. Neurosurgery 2018;83:548-55.

46 Potts MB, Lau D, Abla AA, et al. Current surgical results with low-grade brain arteriovenous malformations. J Neurosurg 2015;122:912-20.

47 Javadpour M, Al-Mahfoudh R, Mitchell PS, et al. Outcome of microsurgical excision of unruptured brain arteriovenous malformations in ARUBA-eligible patients. $\mathrm{Br} \mathrm{J}$ Neurosurg 2016;30:619-22.

48 EM W, El Ahmadieh TY, McDougall CM, et al. Embolization of brain arteriovenous malformations with intent to cure: a systematic review. J Neurosurg 2019;1:1-12.

49 Mosimann PJ, Chapot R. Contemporary endovascular techniques for the curative treatment of cerebral arteriovenous malformations and review of neurointerventional outcomes. J Neurosurg Sci 2018;62:505-13.

50 Teo M, St George J, Lawton MT. Time for BARBADOS after ARUBA trial. Br J Neurosurg 2015;29:635-6. 